\title{
ABSTRACTS
}

\section{NOSE AND ACCESSORY SINUSES}

\author{
Italian Contributions to the Study of Ozana. Ciro Caldera. \\ (The Laryngoscope, 1920, Vol. xxx., p. 31.)
}

Etiology.-Cozzolino thought that ozœna was due, firstly to a scrofulous condition, and, secondly, to bacteriological action. Masini and Genta found a relative decrease in the red blood cells and an increase in the white. Gradenigo considers ozœna a paratubercular disease. Caldera and Bilancioni obtained positive tuberculin reaction in 23 to 34 per cent. of the cases. Ferreri holds that ozœna is the result of a change in the nerve-supply of the nose. In 1878 , Masini stated his belief in the bacterial origin of ozœena. Strazza described a capsulated, Gram negative, non-motile bacterium, showing polar staining and growing easily on ordinary nutritive media. Pes and Gradenigo isolated a Gram-negative bacillus, pathogenic experimentally on animals. Belfanti and Della Vedova found the bacillus mucosus and a pseudo-diphtheria bacillus in sixty-three consecutive cases. Cozzolino found the Abel-Löwenberg bacillus constantly present: he denied the importance of the pseudo-diphtheria bacillus. De Simoni published negative results of experimental inoculations of ozœna in several tuberculous and scrofulous subjects, using the cultures of germs isolated from ozcna crusts. He felt that in addition to the organisms there was needed a peculiar predisposition on the part of the nasal mucous membrane. Later De Simoni pointed out the existence of three classes of bacillus mucosus, and thought that the three classes were derived from a common type, namely, the Friedländer bacillus. Tanturri renewed the experiments of Perez without, however, obtaining any appreciable result as regards atrophy of the turbinals, or any other nasal change. Caldera confirmed Tanturri's results and carried out also the serodiagnostic reaction in many cases of ozcena. In no case did he obtain a complementfixation. Caldera admits the frequency in ozœna of the bacillus mucosus, but denies its specific action. The author believes that ozoena is not a contagious disease; the bacteriological factor accounts for the production of the foul odour, but the malady itself depends upon peculiar organic conditions, such as the lymphatic diathesis. In I9 8, Lasagna repeated the experiments of Perez on rabbits. $\mathrm{He}$ used intravenous and submucous injections. He plugged the nose with gauze soaked in microbic culture, after having first cauterised the 


\section{Nose and Accessory Sinuses}

mucous membrane. He also injected an emulsion of ozœnous crusts under the mucous membrane. The results were negative.

Therapy of Ozcena.-Morra recommended boric acid, aseptol, thymol, resorcin, and menthol. Gradenigo advised iodin and oxygenised water. Malacrida employed essential oil of turpentine. Masucci and Felici reported good results with vibratory massage. Cozzolino advised scraping of the nasal mucous membrane. Antidiphtheritic treatment was tried by Della Vedova, Gradenigo, and others. The good results were purely transitory. Ferreri advised the application of creosote diluted in alcohol and glycerin. Montodo De Francesco published the first case of rapid and permanent recovery from ozœna following an -accidental infection with erysipelas. Dionisio proposed luminous radiations, and obtained good results in one hundred cases. He also reported the first results obtained by submucous injections of warm paraffin in ozœna. De Palma obtained advantageous results by means of the high frequency current. Brugnatelli advocated the use of oxygenised water, and of a 3 per cent. solution of lactic acid. In ig 6 , Caldera recommended plugging the nose for half an hour every day with gauze soaked in ox bile sterilised at $100^{\circ} \mathrm{C}$., or in 3 per cent. watery solution of sodium taurocolate. This treatment is an adjuvant to the favourable results of paraffin therapy.

J. S. Fraser.

The Technique of a Radical Frontal Sinus Operation, which has given me the Best Results. By Dr R. C. Lynch, New Orleans. (The Laryngoscope, January $\mathbf{9 2} \mathrm{r}$, No. I, Vol. xxxi.)

Dissatisfied with the usual methods, Lynch has developed a technique which, he claims, has given him roo per cent. cures. He bases this claim on a series of fifteen cases, over a period of two and a half years. After a very thorough preparation for an aseptic operation, he employs an incision as for the Killian operation, but does not extend the incision beyond the supraorbital notch, unless found necessary later. The periosteum is elevated only from the lower half of the incision. Bone is now removed so as to obliterate the orbital extension of the sinus; the rest of the sinus is curetted free of mucous membrane; this is possible in very large sinuses without opening through the anterior wall. The entire ethmoid labyrinth, and if necessary the anterior wall of the sphenoidal sinus, is cleared away. The wound is closed without external drainage. In each of the fifteen cases there has been "perfect healing, no discharge, no scarring, and a perfect cosmetic result."

Andrew Campbell. 


\title{
Abstracts
}

\section{PERORAL ENDOSCOPY.}

\author{
Functional Signs of Esophageal Cancer. Dr J. Guisez. (Paris, \\ Bulletin D'Oto-rhino-Laryngologie, May r920.)
}

The author gives a short statistical summary, based on 1600 cases personally examined by œsophagoscope; 950, or 59 per cent., were cancers. In a shorter series the condition was found eleven times more often in men than in women; the youngest patient was fourteen, the oldest eighty, but between fifty and sixty years was far the commonest age of incidence. In 55 per cent. the middle third of the œesophagus was affected.

The typical onset is described-a painless difficulty in swallowing is by far the commonest symptom ; the onset is rapid, and bread and meat are found to be the first foods with which difficulty is noticed. This sudden, painless obstruction of a hitherto normal oesophagus, the author considers almost pathognomonic of cancer. Once established, it progresses so that semi-solids and finally liquids cannot be swallowed. The patient knows what size and consistence of bolus he can swallow, and he masticates and salivates his food accordingly. In some cases hypertrophy of salivary glands had produced the appearance of mumps.

Pain is a rare symptom; it is due to extension to intercostal nerves and is usually feit between the shoulder blades. The tumour being usually lateral, dilatation is not common, and " œsophageal vomiting" rare. Progressive wasting is due to the interference with nutrition; "cancerous" cachexia is not observed. Appetite is good, and the wretched patient may die of hunger or thirst, longing for food, which he knows he cannot swallow. The wasting and anæmia is rapidly relieved by successful gastrostomy. Hæmatemesis is rare, but slight bloody streaking of the expectoration is characteristic. A fetid breath is very common. There is no tendency to early appearance of secondary growths, and the patient dies of starvation before the disease extends. The larynx is affected by direct extension, or by involvement of recurrent laryngeal nerves, the left, being involved in the tumour or in periosophageal inflammation.

Latent cases, in which ulceration of a large vessel is the first warning, are occasionally seen. But the common form is usually latent in the sense that the patient does not notice any symptoms until the growth is well established. In the upper end of the osophagus, the pharynx is involved, and pain is early and severe. At the lower end, the signs and symptoms are those of gastric cancer.

Conditions which may simulate cancer are ( 1 ) compression by an aneurysm; (2) cicatricial stenosis, in which a history of trauma is usual; (3) inflammatory stenosis with spasm. Syphilitic stenosis is very rare (. 3 per cent.).

E. Watson-Williams. 


\title{
Peroral Endoscopy
}

\author{
Twoo Cases of Foreign Body in the Left Upper Lobe Bronchus. \\ H. von FienNdt and Y. Meuran. (Acta Oto-laryngologica, \\ Vol. ii., fasc. 4.)
}

In the first case, a boy I 2 years of age, the foreign body, which had been inhaled a fortnight previously, was a part of a musical wind instrument, and consisted of a rubber ring $9 \mathrm{~mm}$. in diameter (which was concentrically fixed in the left lower lobe bronchus), and of a tin piece (in the upper lobe bronchus) attached to it. It was removed under local anæsthesia at the third attempt. Neither physical examination nor $\mathrm{X}$-rays gave any hint as to the site of the foreign body.

The second patient, a girl aged 7 years, had inspired a calf's tooth three months previously. Both the physical signs and an X-ray examination gave indications, although somewhat indefinite, as to the site of the foreign body. The greater part of the tooth lay out of sight in the left upper lobe bronchus, while a small jagged portion of its root was visible in the main bronchus. It was removed at the first attempt under chloroform anæsthesia.

The author remarks that while the second case shows the value of a thorough physical examination, the first is a good example of those in which bronchoscopy is the sole means, not only of treatment, but even of diagnosis.

Thomas Guthrie.

\section{External Esophagotomy for Extraction of a Denture from the Thoracic CEsophagus. MENGoni \& Caucci. (Arch. Ital. di Otol., Vol. xxxi., No. 3, 1920.)}

A man, aged 30, gave a history of having swallowed his upper denture the night before. The denture was a small one carrying two incisors and had one hook. The patient had missed his teeth in the morning and could not find them anywhere. Soon afterwards he felt a weight in his chest and a pain at the top of the sternum. $\mathrm{He}$ made several attempts to vomit. He found that he could not swallow even liquids. He spoke with considerable difficulty, looked ill, and kept his head inclined slightly to the left. Examination of the larynx with the mirror and the finger were negative. X-rays showed the foreign body at the level of the left sternoclavicular articulation with the hook directed upwards. Attempts at removal with forceps were unsuccessful, and Bruenings' œesophagoscope was then tried. The denture could be seen, but attempts at extraction were unsuccessful. As soon as the instrument was removed the patient announced that he felt as though the foreign body was no longer there. He could move his head, speak, and swallow water fairly easily. A second X-ray picture was taken, which showed the foreign body in the same position still, although a sound could now be 


\section{Abstracts}

passed past it. The osophagoscope was again passed under ether to eliminate spasm, but no success was obtained. External operation was then decided on and an incision was made at the root of the neck and the cesophagus exposed. It was opened and explored with the finger, but the foreign body could not be felt. Long forceps were introduced and the object grasped. It was drawn up and removed by movements from side to side. The wound was drained for a few days and rectal feeding instituted. The subsequent recovery was uneventful.

J. K. Milne Dickie.

Foreign Bodies in the Bronchi. IMPERATORI. (The Laryngoscope, 1920, Vol. xxx., p. 386.)

(I) Child, I 4 months old, while playing on the floor, was suddenly seized with a severe strangling attack, which lasted for over an hour. Several attacks of dyspncea and increasing cyanosis during the next four days. Temperature Ior $^{\circ}$, pulse 140 , respiration 48 on admission. Radiographs failed to show anything, except that the diaphragm on the right side was flat. The passage of the $4 \mathrm{~mm}$. tube was somewhat obstructed between the cords. A foreign body was seen in the lower end of the right bronchus, and removed. It proved to be a branching grape stem. The time for this procedure was eight minutes. No anæsthetic was used. Cyanosis, however, increased with inspiratory dyspnœa. Tracheotomy was done but the child died. (2) Male, aged 8 years, inspired a steel ball in play, and for two hours had severe dyspnoa, from which he recovered next day. He complained of pain in the left chest. Radiographs showed a spherical foreign body located in the left bronchus; left side of chest very cloudy. A $7 \mathrm{~mm}$. Jackson bronchoscope was used, and with the aid of a Hubbard hook the ball was dislodged and extracted with the fourpronged Brünings forceps. Recovery. Imperatori remarks on the difference in the radiographs of the chest before and after removal of the foreign body. The latter showed both sides clear.

J. S. FRASER.

Fluoroscopic Bronchoscopy, Esophagoscopy, and Gastroscopy. R. C.

Lynch. (The Laryngoscope, Vol. xxx., I920, No. II, p. 714.)

The author records the case of a patient who inhaled a screw four years previously. On admission there was a pulmonary abscess about two inches in diameter with fairly thick walls. The corresponding bronchus was found entirely closed, but Lynch managed to uncover a path which led into the abscess cavity. Under the guidance of the fluoroscope, forceps were now inserted and seen to grasp the foreign body. It was possible to watch the extraction $49^{8}$ 


\section{Miscellaneous}

of the tube, screw, and forceps until the foreign body was finally delivered.

A baby of two years swallowed a "quarter" which slipped into the stomach, where it lay for two weeks. The fluoroscope determined that it was probably nearer the greater curvature but toward the pylorus. A gastroscope was passed into the stomach, and after moving the patient on the side and then on the back, Lynch finally placed the tube over the body and removed it.

J. S. Fraser.

\section{MISCELLANEOUS.}

$A$ Condemnatory Note on the Use of Parafin in Cosmetic Rhinoplasty. Seymour Oppenheimer. (The Laryngoscope, Vol. xxx., p. 595, 1920.)

Gersuny, in 1900, was the first authority of note to advocate the use of paraffin injections for prosthetic purposes. The method was taken up by a good many skilled and well-recognised surgeons and rhinologists, but also by charlatans and "beauty doctors." As case reports of untoward results have come into the literature with unpleasant frequency in late years, its first burst of widespread popularity has waned considerably. Some of these untoward results are toxic absorption, inflammatory reactions, loss of tissue from sloughing, air and paraffin embolism, primary diffusion of paraffin into other tissues, interference with the alar muscles and consequent embarrassment of respiration, paraffin absorption with loss of cosmetic result attained, dermal hyperæmia and hypersensitiveness, and abscess formation. Retinitis, optic neuritis and sudden blindness have been reported. Oppenheimer holds that the paraffin method is dangerous, even in the hands of the well-equipped surgeon, and doubly dangerous in those of the "beauty doctor."

J. S. Fraser.

Pharyngo-Laryngeal Actinomycosis. G. FerReri. (Arch. Ital. di Laringologia. Vol. xxxix., Nos. 1-2, Aug. 1919.)

Primary actinomycosis of the pharynx or larynx is comparatively rare. The author has only been able to collect one or two cases from the literature. He adds a description of a case which came under his notice during the War.

A sailor came to the clinic with a history of constant sore throats. For some weeks this had been getting worse, and finally there had been hoarseness and some difficulty in breathing.

On examination, the anterior and posterior pillars of the fauces on the right side were seen to be greatly thickened and to have a flattened, papillomatous appearance. This extended to the root of the tongue 


\begin{abstract}
s
and on to the tonsil, which was greatly enlarged and had cheesy matter exuding from the crypts. The disease extended down the right side of the root of the tongue to the glosso-epiglottic fold, the right ary-epiglottic fold and the arytenoid prominence. The right cord was fixed by the infiltration.

Treatment consisted in removing with forceps the greater part of the infiltrated areas and in the administration of iodine by hypodermic injections.

Sections of the tissue showed the typical histological appearance of actinomycosis, and the fungus was easily seen.
\end{abstract}

J. K. Milne Dickie.

\title{
GUILLOTINE WITH A LATERAL SLOT FOR SEVERING PEDICLE OF TONSIL ENUCLEATED BY DISSECTION.
}

By Seymour Jones, Hon. Surgeon, Ear and Throat Hospital, Birmingham.

Tonsils completely dissected out from the tonsillar cleft remain attached by a fibrous prolongation to the side of the tongue. This is usually severed close to the tongue by passing a guillotine (French or English pattern) over a single traction forceps. Scissors are not satisfactory.

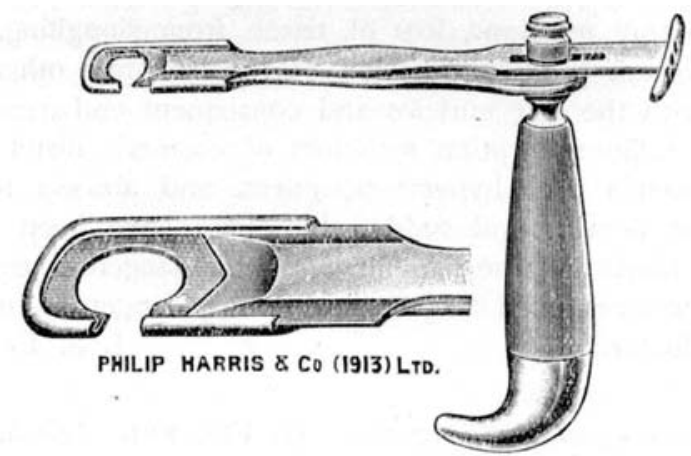

In the modified guillotine shown in the woodcut the slot in the side of the fenestrum allows the guillotine to slide around and engage the pedicle without detaching any of the traction forceps, even if two or three pairs are in use. The side of the fenestrum opposite the slot is reinforced.

Messrs Philip Harris \& Co., Edmund Street, Birmingham, have carefully carried out the author's design and will supply it. 